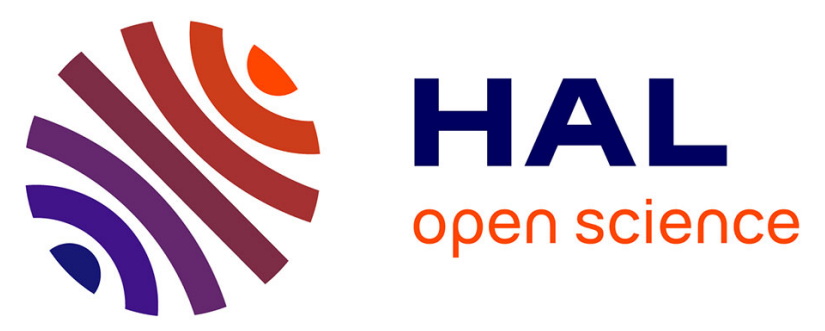

\title{
Evaluation Research of the Influence of Small Hydropower Station for Fuel Project on Social Development Impact
}

Zhengqi He, Dechun Huang, Changzheng Zhang, Bo Wang, Zhijie Ma

\section{- To cite this version:}

Zhengqi He, Dechun Huang, Changzheng Zhang, Bo Wang, Zhijie Ma. Evaluation Research of the Influence of Small Hydropower Station for Fuel Project on Social Development Impact. 8th International Conference on Computer and Computing Technologies in Agriculture (CCTA), Sep 2014, Beijing, China. pp.31-39, 10.1007/978-3-319-19620-6_4 . hal-01420259

HAL Id: hal-01420259

https://hal.inria.fr/hal-01420259

Submitted on 20 Dec 2016

HAL is a multi-disciplinary open access archive for the deposit and dissemination of scientific research documents, whether they are published or not. The documents may come from teaching and research institutions in France or abroad, or from public or private research centers.
L'archive ouverte pluridisciplinaire HAL, est destinée au dépôt et à la diffusion de documents scientifiques de niveau recherche, publiés ou non, émanant des établissements d'enseignement et de recherche français ou étrangers, des laboratoires publics ou privés. 


\title{
Evaluation Research of the Influence of Small Hydropower Station for Fuel Project on Social Development Impact
}

\author{
_taking Majiang of Guizhou Province as an example \\ Zhengqi He ${ }^{12 \mathrm{a}}$, Dechun Huang ${ }^{12 \mathrm{~b}}$, Changzheng Zhang ${ }^{12 \mathrm{c}}, \mathrm{Bo}$ Wang $^{12 \mathrm{~d}}$, Zhijie Ma $^{3 \mathrm{e}}$ \\ ${ }^{1}$ Business School of Hohai University, Nanjing,China, $211100 ;{ }^{2}$ Institute of Industrial Economics of Hohai University, \\ Nanjing,China, $211100 ;{ }^{3}$ China Institute of Water Resource and Hydropower Research (IWHR),Beijing,China, 100038

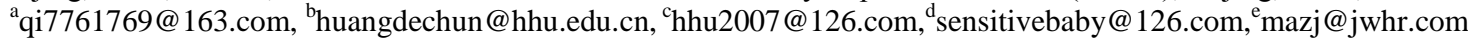

\begin{abstract}
To change energy construction in the backward areas and protect the ecological construction achievements of conversion of cropland to forest, China starts the small hydropower station for fuel project, which has promoted the local social development. To evaluate the influence of the small hydropower station for fuel project on social development in the backward areas, this paper has a comprehensive consideration of the social environment and ecological environment, establishes the relative evaluation index system about influence, introduces the normal cloud model, focusing on the association of fuzzy and random problems in the artificial intelligence, into the evaluation model, and establishes a comprehensive evaluation model based on the normal cloud model and composite entropy weight. Taking the pilot Majiang County of Guizhou Province as an example, this paper evaluates the influence of the small hydropower station for fuel project on social development in the backward areas, and the results are made that the small hydropower station for fuel project has played a role in promoting the social development, and with the implement of the project, the effects become more and more obvious.
\end{abstract}

Keywords: small hydropower station for fuel project, social development, cloud model, composite entropy weight method

\section{Introduction}

Water resources and forest resources are abundant in Southwest China, but for the long-term construction lag of the substitute energy in the rural areas, firewood is still the energy commonly used, which causes soil erosion, low forest coverage rate, deterioration of the ecological environment, and some important achievements of ecological construction like conversion of cropland to forest and natural forest protection cannot be consolidated. To solve the problem, the government has invested lots of money to start the small hydropower station for fuel project. China is rich in the small hydropower resources, and the exploitable capacity is 1.28 billion kilowatts with great exploitation potential, though the exploitation rate is only $36.6 \%$ at present. After years of development, the small hydropower has become an important basis and strong driving force for China's economical and social development in the rural areas. Developing the small hydropower station for fuel project reasonably and efficiently can provide farmers with living fuel and rural energy steadily for a long period, protect the ecological construction achievements of conversion of cropland to forest, reduce farmers' burden of cutting firewood and make great contribution to social development. But a quantitative research is urgently needed to evaluate the project impact on social development and how it can change people's living standard and ecological environment in the backward areas. 


\section{Literature review}

The small hydropower station for fuel project, in a certain sense, belongs to poverty alleviation project. The organizations like World Bank and Asian Development Bank has a deep research on the poverty alleviation project that they participated in. Dani.A[1] considers how to realize the development target for the better mainly through the characteristic analysis of local social culture and organizational structure, and studies the influence of poverty alleviation project on changing demographic, social and cultural characteristics, production activities and residents' living conditions in the backward project areas. Another group of scholars mainly study the patterns for poverty alleviation, taking the pro-Poor Tourism pattern as an example, Caroline Ashley[2] pointed out that tourism development for poverty alleviation can create employment and income opportunities, promote small business management and improve the living standard of the poor. The domestic scholars mainly focus on the patterns for poverty alleviation and poverty alleviation benefits. Wang Sangui[3], who began to study the patterns for poverty alleviation in the early ninety's, pointed out that the economical development patterns can be divided into relying on resources type, asset accumulation type and technology driven type; starting from the benefit evaluation of the poverty alleviation project, Lin Boqian[4] emphasized that poverty alleviation is the most difficult challenge in the process of social development, and he believed that poverty alleviation benefits should be evaluated by both of number measuring method and monetary measuring method, and he proposed the benefit distribution analysis (BDA); taking conversion of cropland to forest project in the West China as an example, Kong Fanbin[5] studied its social impact and had a comprehensive exposition under the background of national microeconomic policy, which offered a way for the scholars to study the social impact evaluation of some important projects.

The current domestic research on the small hydropower station for fuel project mainly concentrates on feasibility evaluation and social development effect evaluation. Liu Tao[6] believes that the project is a public welfare project which focuses on the ecological benefits, and the normal small hydropower evaluation indexes and evaluation methods are unsuitable for the feasibility evaluation of the small hydropower station for fuel project. Shi Canxi[7] constructed three aspects of evaluation indexes during the research on the social impact evaluation, including political benefits, economic benefits and other social benefits (including environmental benefits and spiritual benefits), but using forest coverage rate as the only index evaluation can't truly reflects the environmental benefits; Zou Tifeng[8] noticed the influence of the small hydropower on the ecological environment, and according to the situations like the disordered exploitation caused by the small hydropower development fever, he pointed out various problems that affects the ecological environment during the construction process and proposed reason analysis, and offered a series of policy recommendations that coordinate the small hydropower development and the ecological protection, but he just did the research on the ecological environment without considering other indexes.

All the researches fail to build a perfect evaluation system and comprehensively evaluate the influence of the small hydropower station for fuel project on the social environment and ecological environment. Thus, this paper builds the evaluation index system of the project effect on social development from the two aspects of social environment and ecological environment, proposes the comprehensive method which combines the normal cloud model with composite entropy method, and finally has an empirical analysis through the example of Majiang County of Guizhou Province.

\section{The evaluation index system construction of social development influence of the small hydropower station for fuel project on backward areas.}

The small hydropower station for fuel project aims to improve rural energy structure, consolidate ecological construction achievements, improve rural living conditions, and improve farmers' living standard and habitat environment. Some changes have been taken place in the project areas since the project was implemented, and many 
aspects should be considered to evaluate the project effect on social development. According to the evaluation index system about social development built by Pan Ane[9], other aspects of indexes as well as the single aspect of economic development should be considered to evaluate the social development. Therefore, apart from the economic development, this paper has introduced living quality index and population quality index and reduces the three indexes to the social environment index, together with the ecological environment, building the comprehensive evaluation index system about social development. In the social environment, the economic level is measured by per capita GDP, per capita disposable income, unemployment rate and the third industry proportion in GDP; the living standard is measured by the Engel coefficient, consumer price index, per capita daily leisure time and small hydropower proportion in energy utilization; population quality is measured by natural growth rate of population, per capita schooling years and average span. In the ecological environment, water environment, atmospheric environment, solid waste and environment protection are measured by the eight indexes: per capita annual wastewater emission, sewage treatment rate, per capita annual toxic gas emission, number of polluted days in a year, per capita annual solid waste production, harmless treatment rate of daily garbage, forest coverage rate and environment investment proportion in GDP. Table 1 is the evaluation index system.

Table 1. The evaluation index system of the social development influence of the small hydropower station for fuel project on backward areas

\begin{tabular}{|c|c|c|c|}
\hline \multirow{19}{*}{$\begin{array}{l}\text { the social } \\
\text { development } \\
\text { impact } \\
\text { evaluation of } \\
\text { the small } \\
\text { hydropower } \\
\text { station for } \\
\text { fuel project } \\
\text { on backward } \\
\text { areas }\end{array}$} & \multirow{11}{*}{$\begin{array}{c}\text { social } \\
\text { environment } \\
\text { A }\end{array}$} & \multirow{4}{*}{ economic level $\mathrm{A}_{1}$} & per capita GDP A $A_{11}(\mathrm{RMB})$ \\
\hline & & & per capita disposable income $\mathrm{A}_{12}(\mathrm{RMB})$ \\
\hline & & & unemployment rate $\mathrm{A}_{13}(\%)$ \\
\hline & & & the third industry proportion in GDP A $\mathrm{A}_{14}(\%)$ \\
\hline & & \multirow{4}{*}{ living standard $\mathrm{A}_{2}$} & Engel coefficient $\mathrm{A}_{21}$ \\
\hline & & & consumer price index $\mathrm{A}_{22}$ \\
\hline & & & per capita daily leisure time $\mathrm{A}_{23}$ (hour) \\
\hline & & & small hydropower proportion in energy utilization $\mathrm{A}_{24}(\%)$ \\
\hline & & \multirow{3}{*}{$\begin{array}{l}\text { population quality } \\
\qquad \mathrm{A}_{3}\end{array}$} & natural growth rate of population $\mathrm{A}_{31}(\%)$ \\
\hline & & & per capita schooling years $\mathrm{A}_{32}$ \\
\hline & & & Average life span $A_{33}$ (year) \\
\hline & \multirow{8}{*}{$\begin{array}{c}\text { ecological } \\
\text { environment } \\
\text { B }\end{array}$} & \multirow{2}{*}{$\begin{array}{l}\text { water environment } \\
\qquad \mathrm{B}_{1}\end{array}$} & per capita annual wastewater emission $\mathrm{B}_{11}$ (tons/ person) \\
\hline & & & sewage treatment rate $\mathrm{B}_{12}(\%)$ \\
\hline & & \multirow{2}{*}{$\begin{array}{c}\text { atmospheric } \\
\text { environment } \mathrm{B}_{2}\end{array}$} & per capita annual toxic gas emission $\mathrm{B}_{21}$ (tons/ person) \\
\hline & & & number of polluted days in a year $B_{22}$ (days) \\
\hline & & \multirow{2}{*}{ solid waste $\mathrm{B}_{3}$} & per capita annual solid waste production $\mathrm{B}_{31}$ (tons/ person) \\
\hline & & & harmless treatment rate of daily garbage $\mathrm{B}_{32}(\%)$ \\
\hline & & \multirow{2}{*}{$\begin{array}{l}\text { environment } \\
\text { protection } \mathrm{B}_{4}\end{array}$} & forest coverage rate $\mathrm{B}_{41}(\%)$ \\
\hline & & & environment investment proportion in GDP $\mathrm{B}_{42}(\%)$ \\
\hline
\end{tabular}

\section{The comprehensive evaluation model based on the normal cloud model and composite entropy method}

\section{1 weight determination based on the composite entropy method}

To have a scientific determination of evaluation index weight, this paper combines the subjective weight with the objective weight according to the tendency coefficient method[10] of Yan Yi, If the subjective weight of the evaluation index $\mathrm{j}$ is $W_{j}^{(1)}{ }_{j}$ and the objective weight of which is $W_{j}^{(2)}$, then the combined composite entropy coefficient is:

$$
W_{j}=\gamma W^{(1)}{ }_{j}+(1-\gamma) W_{j}^{(2)}
$$

$\gamma$ is the tendency coefficient, which expresses the important and being tended degree of the subjective weight and the objective weight and to make a better use of the advantages, this paper takes $\gamma=0.5$, that's to say the composite weight is the arithmetic average value. 
Entropy method[11] is a kind of objective weight method, and when using the entropy method, this paper uses $0-1$ standardization to have a normalized processing of the data in the judgment matrix $\mathrm{R}$, and haves the $r_{\max }$ and $r_{\min }$ adjustments of about $20 \%$ to avoid the zero in the standard matrix. The subjective entropy takes the expert scoring method, that's to say by anonymous advice from the relative experts, we can collect, analyze and induce the experts' opinion and determine each index weight according to most experts' experience and subjective judge.

\subsection{The comprehensive evaluation model}

The cloud model is proposed by the Chinese Engineering academician Li Deyi, and it's a conversion model used to deal with the randomness and fuzziness which widely exist in the qualitative concept and it connects the qualitative concept with its qualitative numerical value representation. The digital characteristics in the normal cloud reflects the quantitative concept and quantitative characteristics, which is represented by expectation Ex, entropy En and excess entropy $\mathrm{He}[12]$. According to the digital characteristics (Ex, En, He) in the normal cloud, we use the normal cloud generator to have the cloud droplets, and then finish the mapping from qualitative analysis to quantitative analysis. [13] In the comprehensive evaluation, weight is the key evaluation content, and this paper determines the size of index weight by the composite entropy method. The comprehensive evaluation model and its steps are as follows:

(1) Establish the factor domain of the evaluation object $U=\left\{u_{1}, u_{2}, \cdots, u_{n}\right\}$, establish the comment domain $V=\left\{v_{1}, v_{2}, \cdots, v_{m}\right\}$

(2) Calculate index weight $W=\left\{w_{1}, w_{2}, \cdots, w_{n}\right\}$ by the composite entropy method;

(3) Have a single factor evaluation between factor domain $\mathrm{U}$ and comment domain $\mathrm{V}$, and establish fuzzy relation matrix R. This paper calculates the membership degree of the evaluation factor by the normal cloud model. Let the upper boundary value and the lower boundary value of grade $\mathrm{j}$ a and $\mathrm{b}$, which corresponds to factor $\mathrm{i}$, then the quantitative concept grade $\mathrm{j}$ can be represented by the normal cloud model, and among them

$$
E x=\frac{a+b}{2}
$$

For the boundary value is a transition value from one grade to another grade, and it's a fuzzy boundary which belongs to both of the two corresponding grades, that's to say the membership degree of the two grades is equivalent, therefore it has:

$$
\begin{aligned}
& \exp \left\{-\frac{(a-b)^{2}}{8(E n)^{2}}\right\}=0.5 \\
& \text { It gets } E n=\frac{a-b}{2.355}
\end{aligned}
$$

The excess entropy He expresses the uncertain measure of entropy, which reflects the condensation degree of cloud droplets, the larger the excess entropy value is, the thicker the cloud is, and vice versa. This paper takes the value of excess entropy He according to experience.

(4) Determine the membership degree matrix $Z=\left\{z_{i j}\right\}_{n \times m}$ of cloud model of every grade corresponded to each index. What needs to be noticed is that in order to enhance the evaluation credibility, we need to have a repeated function of normal cloud generator $\mathrm{N}$ times, and calculate the average comprehensive evaluation value under different membership degree situations: $z_{i j}=\sum_{k=1}^{N} \frac{z_{i j}^{k}}{N}$;

(5) get the fuzzy subset $\mathrm{B}$ by the fuzzy conversion of weight set $\mathrm{W}$ and membership degree matrix $\mathrm{Z}$ : $B=W \bullet Z=\left(b_{1}, b_{2}, \ldots . ., b_{m}\right)$

In the equation: $b_{j}=\sum_{i=1}^{n} w_{i} z_{i j}, b_{j}$ expresses the membership degree of the objects to be evaluated to the jth comment. According to the maximum membership degree principle, the ith grade which corresponds to the maximum membership degree is chosen as the comprehensive evaluation result. 


\section{Social development influence evaluation of the small hydropower station for fuel project in backward areas.}

\subsection{Date source}

Majiang county of Guizhou Province is one of the pilot of China's small hydropower station for fuel project, and the project was officially started in 2005 , therefore all the data are derived from the statistical yearbook and local survey research in Majiang county of Guizhou Province from 2006 to 2010.

\subsection{The empirical results and analysis}

On the basis of the evaluation index system of the social development influence on the small hydropower station for fuel project, the evaluation criteria of the project needs to been determined to get the evaluation results conveniently. According to evaluation index system and evaluation index criteria, this paper expresses the corresponding grades of each index with the relative normal cloud model by the formula (1)-(3)( see appendix 1). Assume that $\mathrm{N}=100$, we can use the positive generator algorithm to generate the membership degree matrix, substitute the data of years in the positive generator of the grade cloud model described above, and calculate the average comprehensive evaluation value under the different membership degree situations by a repeated calculation of 100 times. According to the evaluation factor quantitative data of years, get each index weight by composite entropy method:

$\mathrm{W}=\{0.0465,0.0476,0.0392,0.0392,0.0451,0.0453,0.0565,0.0554,0.0549,0.0640,0.0550,0.0481,0.0558,0.0519,0.0519$, $0.0483,0.0563,0.0615,0.0776\}$.

Finally, we can have a fuzzy conversion of weight set $\mathrm{W}$ and membership degree matrix $\mathrm{Z}$ according to step (5) and get the membership degree of the object to be evaluated to the $j^{\text {th }}$ comment and according to the maximum membership degree principle, the $\mathrm{i}^{\text {th }}$ evaluation grade, which is corresponded by the maximum membership degree, was chosen as the comprehensive evaluation result(table2).

Table 2. The evaluation results of the influence of the small hydropower station for fuel of different years on social development

\begin{tabular}{|c|c|c|c|c|c|}
\hline \multirow[b]{2}{*}{ year } & \multicolumn{4}{|c|}{ Membership degree of the normal cloud } & \multirow{2}{*}{$\begin{array}{l}\text { evaluation results of The } \\
\text { normal cloud model }\end{array}$} \\
\hline & Huge promotion & $\begin{array}{c}\text { Greater } \\
\text { promotion }\end{array}$ & $\begin{array}{c}\text { General } \\
\text { promotion }\end{array}$ & $\begin{array}{c}\text { Smaller } \\
\text { promotion }\end{array}$ & \\
\hline 2006 & 0.1831 & 0.0932 & 0.2046 & 0.5482 & Smaller \\
\hline 2007 & 0.1903 & 0.1844 & 0.4641 & 0.3149 & General \\
\hline 2008 & 0.2117 & 0.4842 & 0.2107 & 0.2014 & Greater \\
\hline 2009 & 0.4209 & 0.5119 & 0.1015 & 0.1004 & Greater \\
\hline 2010 & 0.6101 & 0.3517 & 0.0189 & 0.0338 & Huge \\
\hline
\end{tabular}

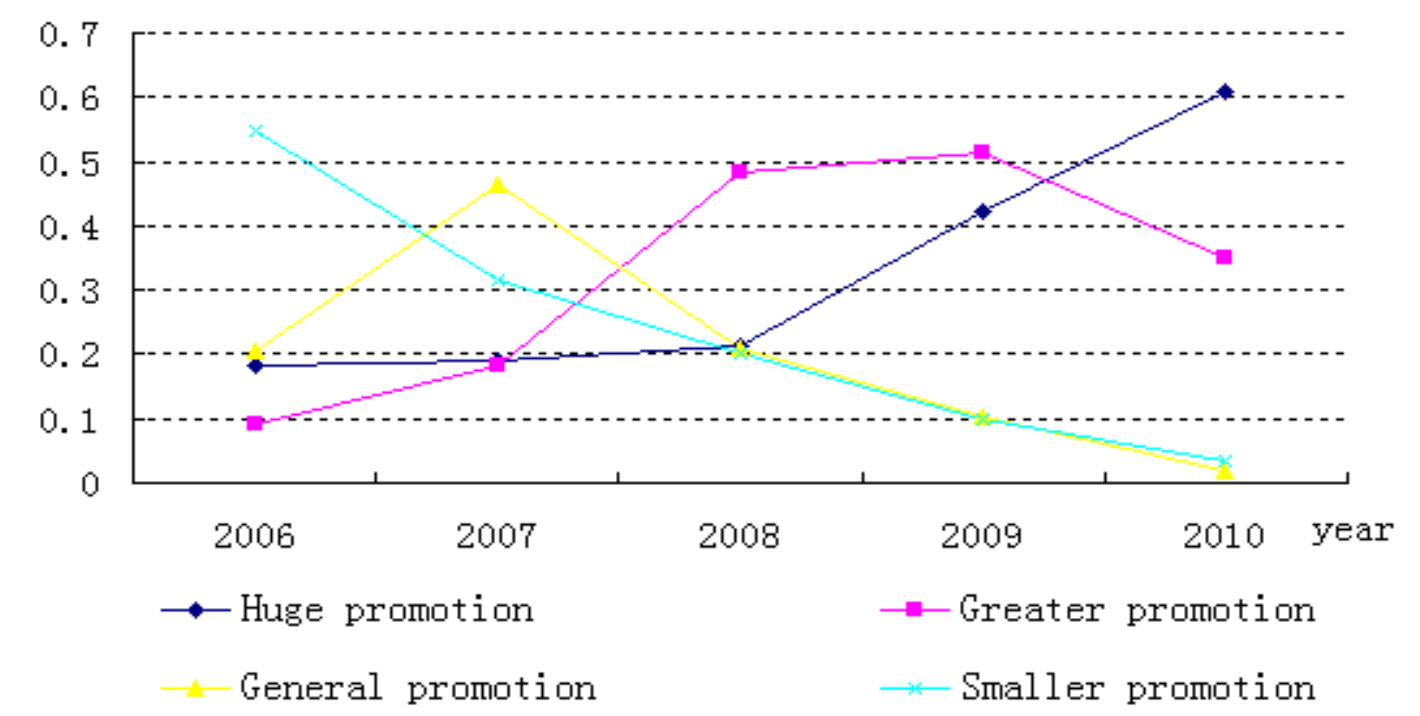

Fig.1. Run chart of the influence of the small hydropower station for fuel project on social development effect According to the evaluation result table and run chart, the small hydropower station for fuel project plays a 
significant role in promoting the social development in Majiang County. (take the year 2012 as an example, the huge promotion: 0.6101, the greater promotion: 0.3517) , from the implement of the project in 2006, the huge promotion effect has increased to 0.6101, comparing to 0.1831 in 2006. From the data analysis, it can been seen that with the implement of the small hydropower station for fuel, the local living quality index $A_{2}$, the atmospheric environment index $\mathrm{B}_{2}$ and solid waste index $\mathrm{B}_{3}$ has changed obviously, and because of the usage of the small hydropower, the living quality has been improved, farmers have more leisure time with enhanced subjective happiness, and for the decrease of the firewood combustion, the atmospheric environment and solid waste pollution is improved, which just fits the purpose of the small hydropower station for fuel project implement, improving the living quality of people in backward areas and improving the ecological environment.

\section{Conclusion}

This paper applies the normal cloud model, which studies the association problems of fuzziness and randomness, into the social development influence evaluation to realize the uncertain mapping of evaluation factor value to comment, randomness as well as fuzziness can be considered in the social development influence evaluation and qualitative analysis and quantitative analysis can be combined. Build the evaluation index system with the starting point of social environment and ecological environment, and determine every index weight by the combination of the subjective and objective composite entropy method, we can have a more scientific reflection of every index weight, and have an evaluation of the influence of the small hydropower station for fuel project in Majiang County of Guizhou Province on local social development.

The results show that: firstly, under the common effects of many factors, the small hydropower station for fuel has improved the local ecological environment, controlled the air pollution and reduced the solid waste pollution. Secondly, the implement of the project has improved the rural energy structure, consolidate the ecological construction achievements, improved the rural living conditions and farmers' living quality. Thirdly, the project has a promote role in widely improving the living quality, further enhancing the economic level and meeting the expected target of the project.

\section{Acknowledgment}

Funds for this research was provided by the Special Program For Key Program for International S\&T Cooperation Projects (2012DFA60830).

\section{References}

1. Dani.A. Social Analysis Sourcebook: Incorporating Social Dimensions into Bank-Supported Projects[J]. The World Bank Social Development Department. Washington, DC, 2003.

2. Ashley C, Goodwin H I, Boyd C. Pro-poor tourism: putting poverty at the heart of the tourism agenda[M]. London: Overseas Development Institute, 2000.

3. Wang Sangui. Anti-poverty and Government Intervention [J]. Management World,1994,3(1).

4. Lin Boqiang. Income Distribution Analysis of Investment Projects and Poverty Alleviation Benefit Assessment [J]. Journal of Financial Research, 2007 (03A): 175-190.

5. Kong Fanbin. Social Influence Research on Conversion of Cropland to Forest in West China[J]. Journal of Jiangxi University of Finance and Economics, 2006(1): 50-52.

6. Liu Tao. Feasibilty Evaluation of the Small Hydropower Station for Fuel Ecological Protection Project Based on Grey AHP[J]. Journal of Water Resources and Water Engineering, 2006,17(3):46-49.

7. Shi Canxi. Comprehensive Evaluation of the Social Benefits of the Small Hydropower [J]. Small Hydropower, 1998 (3): 1-4.

8. Zou Tifeng, Wang Yanfang, Fei Liangjun. Analysis of the Ecological Environment Protection Problems of the Small Hydropower Development[J]. China Rural Water and Hydropower, 2008(3):97-98. 
9. Pan Ane. Comprehensive Evaluation of Economic and Social Development of Wuhan City Based on Principal Component Analysis [J]. China Soft Science, 2005(7):118-121.

10. Yan Yi. A study on Supply Chain Coordination of Engineering Project Manufacturing System with Large Logistics its Synergetic Evaluation[D], Tientsin University, 2007.

11. Zhang Sui, Zhang Mei. Science and Technology Evaluation Model and Empirical Study Based on Entropy Method[J]. Chinese Journal of Management, 2010, 7(1): 34-42.

12. Li Deyi, Liu Changyu. The Universality of the Normal Cloud Model [J]. Engineering Sciences, 2004, 6(8): 28-34.

13. Wang Shouxin, Zhang Li, Li Hesong. A Subjective Trust Evaluation Method Based on Cloud Model[J]. Journal of Software, 2010,21(6): 1341-1352.

Appendix 1.The normal cloud standard of the evaluation index of the social development influence on the small hydropower station for fuel project

\begin{tabular}{lcccc}
\hline \multirow{2}{*}{ Index } & \multicolumn{2}{c}{ The social development influence on small hydropower station for fuel project } \\
\cline { 2 - 5 } & Huge promotion & Greater promotion & General promotion & Smaller promotion \\
\hline $\mathbf{A}_{11}$ & $(7750,636.94,80)$ & $(6250,636.94,80)$ & $(4750,636.94,80)$ & $(3250,636.94,80)$ \\
$\mathbf{A}_{\mathbf{1 2}}$ & $(3400,169.85,60)$ & $(3000,169.85,60)$ & $(2600,169.85,60)$ & $(2200,169.85,60)$ \\
$\mathbf{A}_{\mathbf{1 3}}$ & $(3.5,0.085,0.02)$ & $(3.7,0.085,0.02)$ & $(3.9,0.085,0.02)$ & $(4.1,0.085,0.02)$ \\
$\mathbf{A}_{\mathbf{1 4}}$ & $(48,0.85,0.2)$ & $(46,0.85,0.2)$ & $(44,0.85,0.2)$ & $(42,0.85,0.2)$ \\
$\mathbf{A}_{\mathbf{2 1}}$ & $(58,1.69,0.4)$ & $(62,1.69,0.4)$ & $(66,1.69,0.4)$ & $(70,1.69,0.4)$ \\
$\mathbf{A}_{\mathbf{2 2}}$ & $(97.5,1.27,0.3)$ & $(100.5,1.27,0.3)$ & $(103.5,1.27,0.3)$ & $(106.5,1.27,0.3)$ \\
$\mathbf{A}_{\mathbf{2 3}}$ & $(2.8,0.17,0.04)$ & $(2.4,0.17,0.04)$ & $(2.0,0.17,0.04)$ & $(1.6,0.17,0.04)$ \\
$\mathbf{A}_{\mathbf{2 4}}$ & $(21,2.55,0.6)$ & $(15,2.55,0.6)$ & $(9,2.55,0.6)$ & $(3,2.55,0.6)$ \\
$\mathbf{A}_{\mathbf{3 1}}$ & $(7.35,0.13,0.03)$ & $(7.05,0.13,0.03)$ & $(6.75,0.13,0.03)$ & $(6.45,0.13,0.03)$ \\
$\mathbf{A}_{\mathbf{3 2}}$ & $(9.3,0.085,0.02)$ & $(9.1,0.085,0.02)$ & $(8.9,0.085,0.02)$ & $(8.7,0.085,0.02)$ \\
$\mathbf{A}_{\mathbf{3 3}}$ & $(72,0.85,0.2)$ & $(70,0.85,0.2)$ & $(68,0.85,0.2)$ & $(66,0.85,0.2)$ \\
$\mathbf{B}_{\mathbf{1 1}}$ & $(14.5,1.27,0.3)$ & $(17.5,1.27,0.3)$ & $(20.5,1.27,0.3)$ & $(23.5,1.27,0.3)$ \\
$\mathbf{B}_{\mathbf{1 2}}$ & $(51.5,3.82,0.9)$ & $(42.5,3.82,0.9)$ & $(33.5,3.82,0.9)$ & $(24.5,3.82,0.9)$ \\
$\mathbf{B}_{\mathbf{2 1}}$ & $(0.067,0.002,0.001)$ & $(0.071,0.002,0.001)$ & $(0.075,0.002,0.001)$ & $(0.079,0.002,0.001)$ \\
$\mathbf{B}_{\mathbf{2 2}}$ & $(38.5,1.27,0.3)$ & $(41.5,1.27,0.3)$ & $(44.5,1.27,0.3)$ & $(47.5,1.27,0.3)$ \\
$\mathbf{B}_{\mathbf{3 1}}$ & $(1.7,0.085,0.2)$ & $(1.9,0.085,0.2)$ & $(2.1,0.085,0.2)$ & $(2.3,0.085,0.2)$ \\
$\mathbf{B}_{\mathbf{3 2}}$ & $(44,1.69,0.4)$ & $(40,1.69,0.4)$ & $(36,1.69,0.4)$ & $(32,1.69,0.4)$ \\
$\mathbf{B}_{\mathbf{4 1}}$ & $(73,3.39,0.8)$ & $(65,3.39,0.8)$ & $(57,3.39,0.8)$ & $(49,3.39,0.8)$ \\
$\mathbf{B}_{\mathbf{4 2}}$ & $(1.9,0.085,0.2)$ & $(1.7,0.085,0.2)$ & $(1.5,0.085,0.2)$ & $(1.3,0.085,0.2)$ \\
\hline
\end{tabular}

